\title{
Recent Advances and Challenges in Induction Welding of Reinforced Nylon in Automotive Applications
}

\author{
Val A. Kagan \\ Technical Adviser \\ Russell J. Nichols \\ ASHLAND SPECIALTY CHEMICAL COMPANY
}

\begin{abstract}
The advantages of magnetic implant induction welding $\left(\text { Emabond }^{\mathrm{TM}}\right)^{1}$ technology for various thermoplastics were widely discussed since the mid-eighties in a series of technical articles and reports, and presented to the professional Societies (SAE, SPE, SME, etc). In 19982003, we reported to SAE International our technical achievements in optimizing the mechanical performance of welded nylon $(6,66,6 / 66,46$, etc.) using frictional (linear and orbital vibration, ultrasonic), contact (hot plate), and non-contact (laser through-transmission) welding technologies.
\end{abstract}

Our recent developments focused on optimization of mechanical performance of induction welded nylon 6 , which has reached a new performance level through continuous improvement of magnetic implant induction welding technology, including properties of the formulated magnetic implant material, new equipment, SPC process control, optimized design of joints, etc. In the current paper, we will try to enhance the understanding of the automotive engineering community regarding the usefulness, unique capability, and applicability of the recently improved Emabond welding technology in the design for heavy-duty and loadbearing automotive plastic parts where requirements for safety and durability are the first priority and fiber-glass reinforced nylon based plastics are widely used.

\section{INTRODUCTION}

Due to the significant increase in use of reinforced thermoplastics in automotive heavy-duty and loadbearing applications, advanced joining and welding methods are becoming a very important contributor to basic design and manufacturing methods. These

\footnotetext{
${ }^{1}$ Emabond $^{\mathrm{TM}}$ - is trade name of Ashland Specialty Chemical Company
}

methods are used to attain targets associated with weight and cost reductions while concurrently providing enhanced performance, safety, and durability.

Fundamentals of the current welding technologies of thermoplastics are described in detail in [1-5]. These technologies all share one common characteristic; for welding of thermoplastics, the process must create heat and melt at the surfaces to be joined for the weld interphase formation. The future trends for the 21 st century in sophisticated methods of joining, fastening, and welding of thermoplastics including various industrial applications are presented in [4]. In general, there are three following basic methods of welding of thermoplastics (Table 1):

- Mechanical movement (frictional: linear and orbital, spin, ultrasonic, kinetic, etc.).

- External (hot plate, hot bar, hot gas/air, extrusion, over-molding).

- Electromagnetic (induction, high frequency, and infra-red/laser, etc.).

Table 1. Basic methods of the heat generation for welding of thermoplastics components.

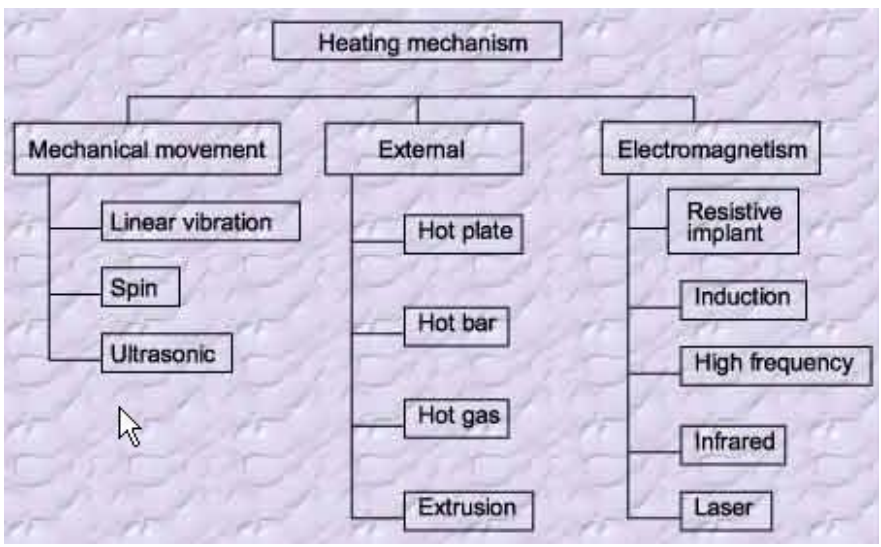


Each heating mechanism (heat generation method) has both some visible advantages and some (possibly hidden) disadvantages, depending on the application requirements, such as part design, end-use performance, and material type and composition (including the specific performance impact of fillers, reinforcements, impact-modifiers, pigments, etc).



Figure 1. Typical uses of engineering thermoplastics in automotive under-the-hood components

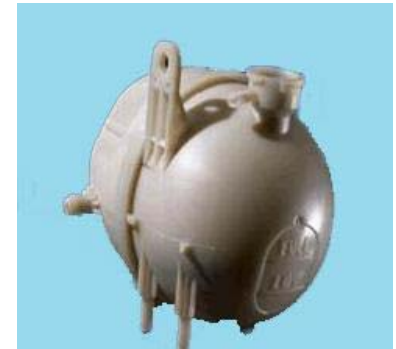

a



C

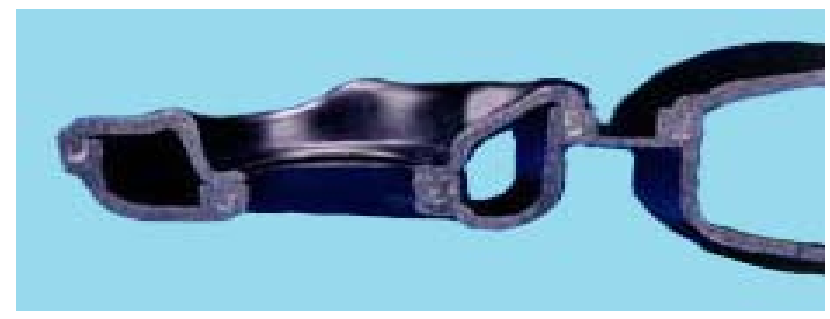

d

Figure 2. Induction welded automotive components from 30-33 wt. \% fiber-glass reinforced nylon 6: a) radiator overflow tank, b) power steering reservoir, c) intake resonator, $d$ ) resonator weld detail
Nylon (polyamide) is widely used in the design of many welded automotive under-the-hood components (Figures 1 and 2) such as air intake manifolds (AIM'S), resonators, fluid reservoirs, etc. In [5-6] we discussed advantages and some disadvantages of frictional (linear vibration, orbital vibration, ultrasonic), external (hot plate) and laser through-transmission welding (LTTW) for various nylon based unfilled, impact-modified, and glass-fiber reinforced plastics (nylon 6, 66, 6/66, 46, amorphous and high temperature resistance HTN series, etc). Typically, frictional welding technologies require use of butt-joint configurations (Figure 3). Most frequently, induction welding uses a tongue-in-groove design (Figure 4).



Figure 3. Typical design geometry of a straight butt-joint for linear vibration welding (including provision for flash traps)

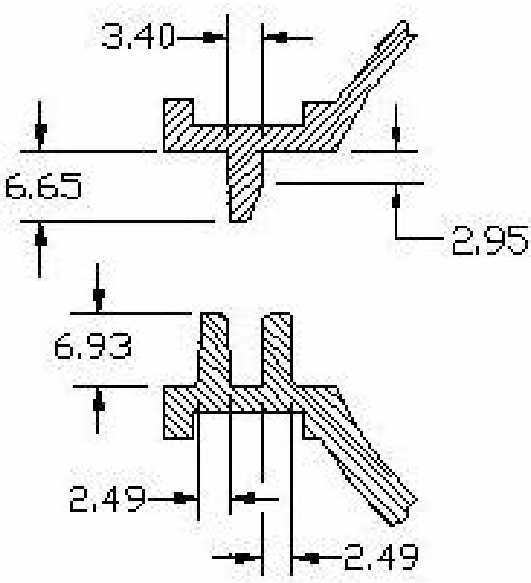

Figure 4. Schematic presentation of a typical tongue-ingroove design for induction welding applications

Mechanical performance of linear vibration welded parts designed with butt-joints depends on the width of the joint. In turn, the width of the butt-joint is limited by the thickness of the walls of joined/welded parts [6-7]. Flash traps (see Fig. 3) are used to limit the outflow of weld material for aesthetic reasons. 
The width of the joint with flash traps also depends on the frequency of mechanical oscillations, which may vary from $100 \mathrm{~Hz}$ to $260 \mathrm{~Hz}$ (Figure 5). Frequency of oscillations varies with the type of welding machine and the weight/size of welded plastic components.

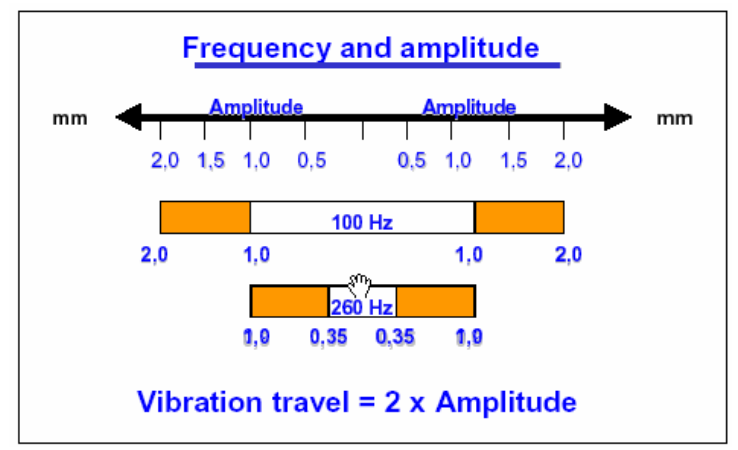

Figure 5. Influence of welding frequency and weld amplitude on linear vibration welding processes and butt-weld design

Previously we demonstrated the positive influence of weld amplitude on mechanical performance of welded nylon [5]. Increasing amplitude results in a corresponding increase in tensile strength. The same effects are typical for frequency of oscillations. When frequency is decreased, the amplitude will be increased with a corresponding increase of the width of the flash trap areas (see Figures 3 and 5). This relation may bring some additional limitations to geometry of designed parts where the width at the weld area is critical factor. Mechanical performance of a tongue-ingrove joint depends in general on the length and thickness of the tongue $[8-9,11]$. As a rule, the length of joint (tongue) is not limited by thickness of the wall of a joined part. Due to these principal differences in weld design, published results on the mechanical performance of induction welded nylon were limited to end-use performance such as burst pressure for developed applications, and tensile strength has not been used as the design parameter.

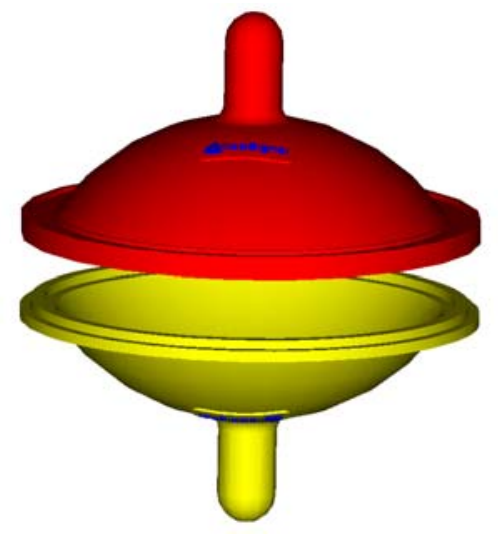

Figure 6: Geometry of the "two-shelf" system ("Cereal Bowls")
Some correlations between functional performance of the induction welding process and the nominal strength data for tongue-in-groove systems molded from PP, PC and PBT based plastics were discussed and analyzed in [11]. Unfortunately, similar strength data for tongue-ingroove systems for induction welded nylon have not been discussed in previously published studies.

For these reasons, we initiated a special evaluation and chain-optimization study which allows us to make critical comparisons of the above mentioned welding technologies using a uniform test and evaluation model. See the geometry of two-shelf system ("Cereal Bowls") used for welded nylon performance evaluation and optimization shown in Figure 6, which utilized a complex of advantages of two welded together shelves. The same injection molded shelves were used in our previous comprehensive study [12] on efficiency of linear vibration welding of fiber-glass reinforced nylon.

\section{DIFFERENCES AND SIMILARITIES OF INDUCTION AND FRICTIONAL WELDING}

\section{BASIC PARAMETERS FOR LINEAR VIBRATION WELDING}

Previously we analyzed and demonstrated basic technical advantages of vibration welding process for various nylon-based plastics. It was reported previously [13] that for glass-fiber reinforced nylon, the maximum weld strength for the butt-joint is approximately equal to or less than the strength of the matrix or base material (Figure 7).

For impact modified grades, we need additionally to take into account the decrease of mechanical properties due to influence of impact modifiers which positively increase the ductility of system and negatively affect on the strength (see Figure 7, right side).

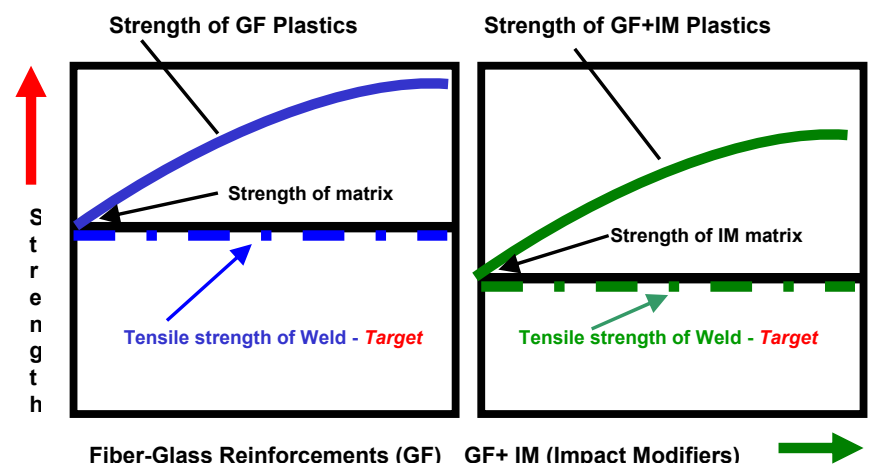

Figure 7. The influence of reinforcements and impact modifiers on tensile strength of welded nylon

Figure 8 demonstrates the positive effects of the reduced weld pressure on weld performance, but welding cycle time is going to be increased. Optimizing reduced pressure is a key parameter for many welding 
processes. More detailed results related to optimization of linear vibration welding of nylon may be obtained from $[5-6,12-14]$


Figure 8. The influence of welding (in-process) pressure on tensile strength of welded nylon (courtesy of University of Erlangen-Nuremberg, Germany)

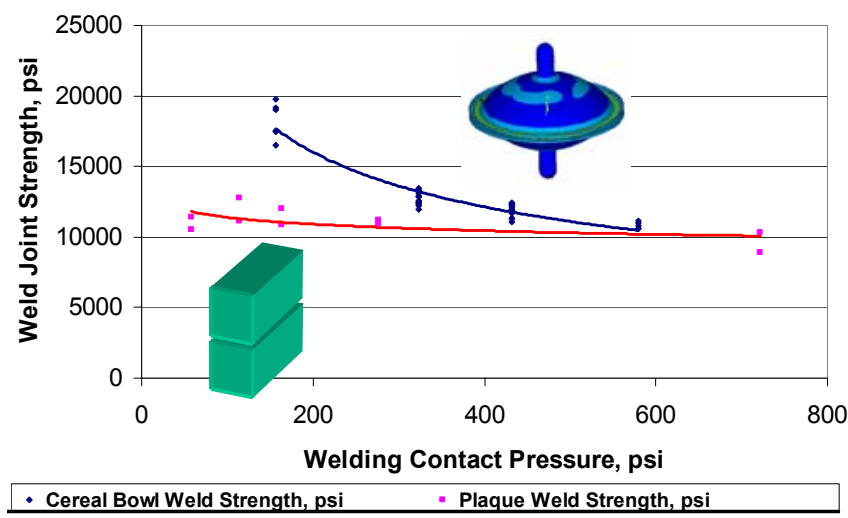

Figure 9. Mechanical performance of vibration welded nylon for the straight plaques and "Cereal bowls" system

\section{BASIC PARAMETERS FOR INDUCTION WELDING}

The fundamental parameters of induction welding are described and analyzed in detail in [1-3, 9-10]. In general, induction welding describes joining technique(s) where heating is generated by an induction field acting upon a magnetic susceptor implant. The key process steps can be described by means of the schematic diagram in Figure 10. In principle, any thermoplastic polymer that melts on heating can be welded by the induction welding process.

One of the features governing the efficiency of induction welding is the magnetic permeability of the susceptor implant, which is a composite of polymer(s) with particulate ferromagnetic fillers.

The second feature, essential to application performance, is the flexibility in joint geometry (width and length), which may utilize the advantages of butt and/or tongue-in-groove joints for enhanced mechanical performance in the automotive heavy-duty and loadbearing applications. The length of the joint (tongue) is not limited by the thickness of a wall.
The third factor governing the ultimate strength of the joint is the compatibility of the polymer(s) used for the magnetic susceptor implant with the substrate materials to be joined. By tailoring an implant properly it is also possible to weld dissimilar plastics materials ("material 1 " and "material 2" by using an implant that is compatible with both the thermoplastics/materials (1 and 2) being welded.

The fourth factor related to ultimate joint performance is optimizing processing parameters, which will bring both the RF targeted implant and the joined materials to the desired temperature under appropriate weld pressure, hold time, and cooling. The key induction welding processes showing phases before, during, and after welding and kinetics of welding are illustrated in Figure 10.

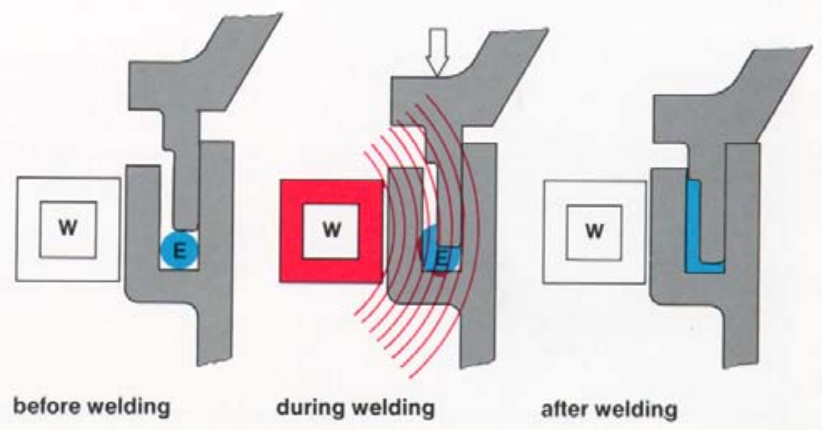

Figure 10. The key induction welding process phases

The current study focused on the optimization of the magnetic implant induction welding process with the objective of increasing mechanical performance (measured by burst pressure at failure/cracking of weld) of the joint by $30 \%$ for welded 33 wt.\% fiber-glass reinforced nylon 6 , which is used in many automotive under-the-hood and similar applications.

Optimized mechanical performance of welded nylon components is dependent upon numerous factors including overall part design, selection of appropriate geometry of the joint, the composition and quality of the magnetic implant material, and selection of weld process conditions. Better understanding of these interactions would promote the selection of this technology for joining of reinforced thermoplastics in the automotive heavyduty and load-bearing applications.

\section{ELECTROMAGNETIC HEATING PRINCIPLES}

Induction welding of polymers takes advantage of the fact that high frequency (HF) energy propagates through free space (in contrast, low frequency (LF) energy propagates via electron migration within a metallic conductor. In this system, radio frequency (RF) energy in the $2-10 \mathrm{MHz}$ range is applied through a coil that conforms closely to the parts to be bonded. Heating occurs principally by hysteresis loss [10], and to a slight degree, by eddy current (or $I^{2} R$ ) heating of the particulate ferromagnetic susceptor applied at the bond- 
line. The heating rate is determined by the magnetic permeability, or magnetic susceptibility, of the implant at the bond interface. The magnitude of the hysteresis loss is described by the area enclosed in a plot of the induction field $(B)$ versus the magnetic field $(H)$ as shown below:

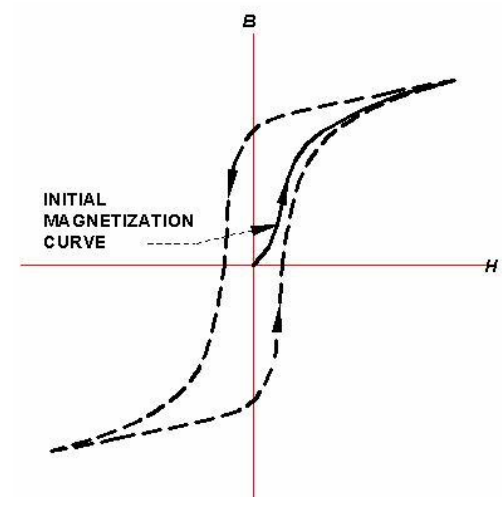

Figure 11. Typical magnetic hysteresis loop

\section{BASICS OF INDUCTION WELDING SYSTEMS}

Induction welding of thermoplastic materials has been in commercial use for over twenty years [8-9]. Systems range in complexity from highly automated multi-station units with integrated robotic material handling to simple single-station units with manual loading and unloading of parts.

Common elements shared by all systems (independent of the level of complexity) include the following: a radio frequency (RF) energy source, a coil to deliver the energy closely adjacent to the bond-line, a press (with associated tooling) to hold the parts in position during the weld cycle, controls to assure reliable and consistent operation and requisite safety features. In addition to the electro-mechanical components of the welding system, material science also has a role in selection of both the magnetic susceptor material and the polymer matrix material.

\section{EXPERIMENTAL PROGRAM AND RESULTS}

\section{EXPERIMENTAL APPARATUS}

\section{$\underline{\text { Tongue-in-Groove Joint, Coil and Fixture Design }}$}

The interrelationship between the geometry of the joint and the spatial positioning of the RF coil determines the overall efficiency of energy transfer from the RF coil to the magnetic susceptor material placed in the joint. The reflector is a non-energized coil that directs the magnetic lines of flux toward the bondline. The parts to be joined are also subject to a modest clamping force during joining to assure adequate flow of the susceptor material, and containment of the parts during cooling.

In this case, the test mold is shaped like a "Cereal Bowl" (see Fig, 6), and it is equipped with an insert tool so that different geometry tongue-in-groove weld joints can be molded in, so one mold can make both upper and lower shell of the test sample. For the present study on induction welding technology, the tongue molded into the upper shell is $3.4 \mathrm{~mm}$ thick and $6.65 \mathrm{~mm}$ long with a mating groove molded into the lower shell. The arrangement of the parts to be joined in relationship to the RF coils is illustrated below in Figures 12 and 13.

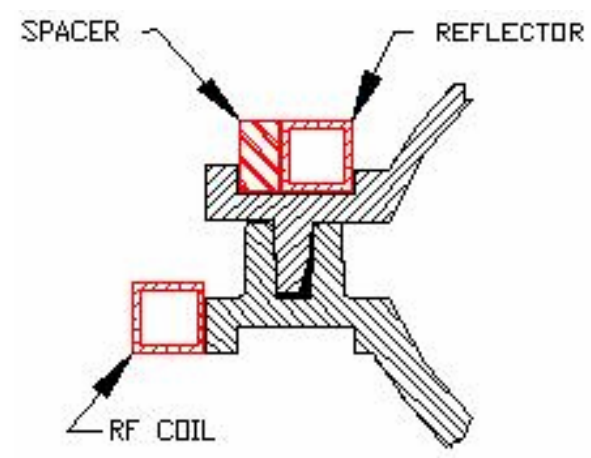

Figure 12. Details of tongue-in-groove joint and RF coil and reflector


Figure 13. Details of induction welding system: a) coil connection to RF generator, b) RF coil, c) RF coil with lower half of cereal bowl in place, d) RF coil with both halves of cereal bowl in place, e) bowl with upper (reflector) coil positioned relative to the cereal bowl for illustrative purposes (it is normally fastened in the upper tooling block), f) coil assembly in supporting tooling 


\section{$\underline{\text { Induction Welding Parameters }}$}

Injection molded fiber-glass reinforced 33 wt. \% nylon 6 samples (cereal bowls) were induction welded initially using two principal processing parameters as variables:

- weld time

- low pressure set-point

After initial screening was completed, further process refinements were added to optimize welding performance:

- weld time @ low pressure

- weld time@ high pressure

- cooling time

\section{Burst Testing}

The welded test samples were connected to a Barbee P200 portable hydrostatic tester, at room temperature. The welded sample was initially filled with room temperature water and then pressurized with air. The air pressure was applied. The burst pressure was recorded using a 0-400 PSI Noshok ${ }^{\circledR}$ oil-filled pressure gauge with a re-settable indicator. Burst testing was conducted within one hour of induction welding.

\section{ADVANTAGES OF THERMAL IMAGING OF THE MAGNETIC IMPLANT MATERIAL}

One of the methods used to characterize and optimize the induction welding process and mechanical performance is to capture thermal images of the susceptor compound in the open groove of the part when the RF field is applied.

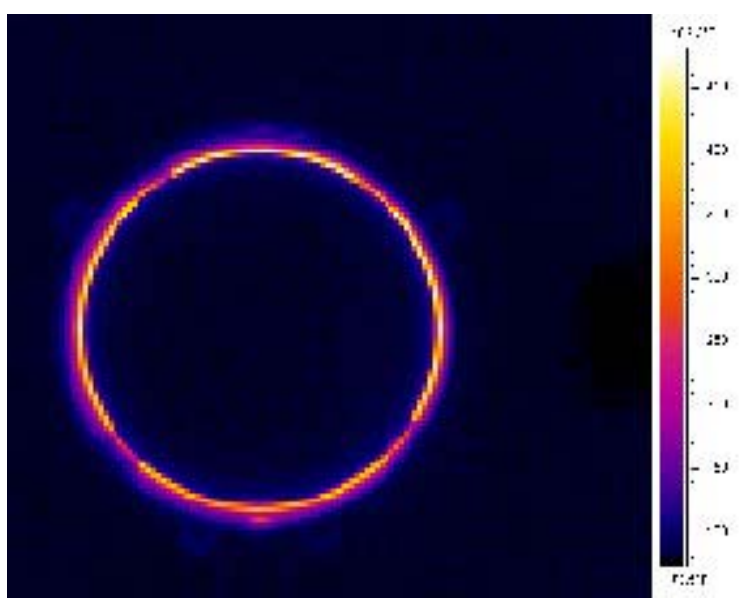

Figure 14. Typical thermal image of lower half of cereal bowl with magnetic implant material in active RF field

Individual images can be used to identify heating uniformity throughout the part or multiple images of a specific location can be tracked and plotted to identify heating rate as a function of time.
The data shown in Figures 14 and 15 were obtained using a FLIR Systems Thermacam SC300 long wave focal plane array (FPA) thermal analysis package.

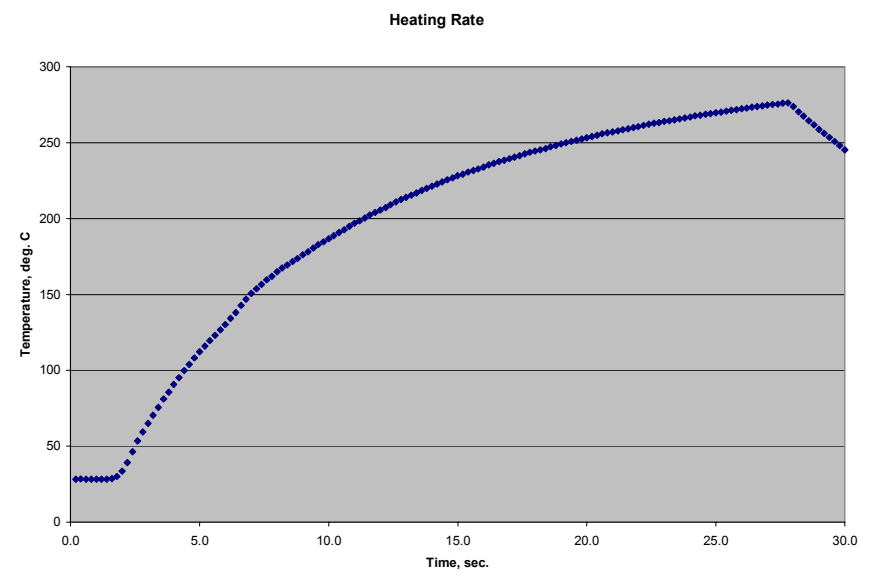

Figure 15. Typical heating rate of magnetic implant material as a function of time in the RF field

\section{STATISTICALLY DESIGNED EXPERIMENT (DOE)}

To establish initial process conditions for any new part, it is appropriate to perform a screening DOE. In this project, a two-factor, two-level, fractional factorial experimental design with an added center point and three replicates was selected. The power of a statistically designed experiment is that one need not hit the desired target with the initial results to establish the direction toward an appropriate process window. A contour plot of the screening DOE result is shown in Figure 16.



Figure 16 - Screening DOE contour plot to establish initial process conditions

Table 2. Progress toward optimized process conditions

\begin{tabular}{|c|c|c|c|c|}
\hline $\begin{array}{c}\text { Weld } \\
\text { Time @ } \\
\text { Low } \\
\begin{array}{c}\text { Pressure } \\
\text { sec }\end{array}\end{array}$ & $\begin{array}{c}\text { Applied } \\
\text { Force, } \\
\text { Lbs/in of } \\
\text { Bondline }\end{array}$ & $\begin{array}{c}\text { Weld } \\
\text { Time @ } \\
\text { High } \\
\text { Pressure } \\
\text { sec }\end{array}$ & $\begin{array}{c}\text { Applied } \\
\text { Force, } \\
\text { Lbs/in of } \\
\text { Bondline }\end{array}$ & $\begin{array}{c}\text { Cool } \\
\text { Time, } \\
\text { sec. }\end{array}$ \\
\hline 11 & 10 & 5 & 47 & 20 \\
\hline
\end{tabular}


This result indicated that to increase the burst pressure, further reductions in weld time and low pressure setpoint were required. The improved weld process conditions are given in Table 2.

In this performance evaluation, hollow cereal-bowls of the same overall dimensions were utilized as those used for the study of vibration welding. However, the significant difference in joint design (butt-joint vs. tongue-in-groove shear joint) results in quite different failure mechanisms. At previously optimized processing conditions for vibration welded fiberglass reinforced nylon, the tensile strength of butt-joints was equal to the tensile strength of unfilled (non-reinforced) resin (matrix), and was independent of reinforcement. In the case of the tongue-in-groove shear joint, the quality of the local reinforcement (i.e., glass fibers in the tongue and groove elements) permits performance greater than that of the non-reinforced base polymer.

\section{MECHANICAL PERFORMANCE DATA}

A series of bowls were welded at the optimized test conditions given in Table 2. Average burst strength of 192 psi was observed with a maximum burst strength of 218 psi and a minimum burst strength of 177 psi. Vibration welding data was previously discussed in [12].



Figure 17. Recent Advances in Induction Welding Strength for Optimized Tongue-in-Groove Joint Design and Processing Conditions ${ }^{2}$

Mechanical performance of the induction welded cerealbowl system by the burst pressure criteria depends both on the level of reinforcement and on local distribution of the reinforcing materials in the tongue and groove sections.

\section{FAILURE MODE ANALYSIS}

As a result of both joint design and process optimization activities, the common failure mode among these samples was fracture through the tongue (Figure 18). The specimens with fractures through the lower end

\footnotetext{
${ }^{2}$ Burst pressure for vibration welding was developed for butt-welded joint with flat surfaces [12].
}

(nearer the tip) of the tongue correspond with lower burst strengths, while fractures through the upper end (nearer the root) of the tongue correspond with the higher burst strengths.

Fracture through the tongue implies a flexural affect related to the geometry of the bowl system, rather than just a local joint geometry issue. Further, it is evident that the strength of the tongue is dependent upon the fiber-glass orientation and distribution.



a

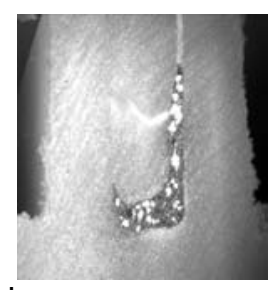

b



C
Figure 18 - Tongue fractures a) nearer the tip of the tongue, b) nearer the root of the tongue, c) no tongue fracture evident

\section{CONCLUSION}

Our recent developments focused on the optimization of mechanical performance of induction welded fiber-glass reinforced nylon 6 .

- The data demonstrate that induction welding can meet increased performance demands while also minimizing the wall thickness. Induction welding provided an overall improvement in average burst strength of $25 \%$ versus historical data.

- The common failure mode observed, fracture through the tongue, suggests that further strength optimization can be obtained by redesign of the joint to increase the thickness of the tongue, even within the overall joint width constraints of the present bowl design.

- The apparent strength limitation in this element appears to be dependent upon the distribution of the reinforcing glass fibers in the local region. It is believed that larger cross-section in the tongue would assure better distribution of glass fibers during the injection molding process.

- It is believed that this data is generally applicable to other reinforced plastic systems.

The results presented in this study will help plastic part designers, material developers, and manufacturers, choose optimized induction welding conditions for polyamide/nylon parts in a wide range of automotive applications.

\section{ACKNOWLEDGMENTS}


The authors wish to thank Juan Ruiz for injection molding, Rommel Velasco, Brian Agosto and Joshua Guerra for welding and testing, and Raymond Trunk for tooling. Special thanks go to Drew P. LaMarca and Steve Chookazian for help in preparing this study for publishing. Their contributions are greatly appreciated.

\section{REFERENCES}

1. Plastics and Composites Welding Handbook, Edited by D. A. Greweel, A. Benatar, and J. Park, 407 pages, Hanser Publisher, Munich (2003).

2. Rotheiser, J., "Joining of Plastics", 535 pages, Hanser Publisher, Munich (1999).

3. Handbook of Plastics Joining - A Practical Guide, Plastic Design Library (PDL), 586 pages, Norwich, NY (1999).

4. Messer, R., "Trends in Key Joining Technologies for the Twenty-First Century", Assembly Automation, Vol. 20, No. 2, pp. 118-128, MCB University Press (2000).

5. Kagan, V., "Alternatives for Joining Technologies for Under-the-Hood Plastic Parts: From Linear Vibration to Laser Transmission Welding", POWERTRAIN INTERNATIONAL, Vol. 3, No. 3, pp. 24-35, Detroit (2000).

6. Kagan, V., "Laser Welding Technology of Nylon: A Challenge for Innovative Design of Welded Parts", Advanced Automotive Laser Applications, Vol. 28, Proceedings of the 2003 Automotive Laser Applications Conference \& Exposition, pp. 53-65, Ann Arbor, Michigan (2003).

7. Stokes, S., "Assessment of Geometries for Determining Strength of Thermoplastic Vibration Welds", Journal of Material Science, pp. 2393-2403, Vol. 35 (2000).

8. Chookazian, S., "The Emabond" ${ }^{\mathrm{TM}}$ Process for Thermoplastic Assembly", Electromagnetic Welding, 11 pages (1999).

9. Chookazian, S., "Bonding with Electromagnetic Energy", Assembly, (January 2000).

10. Nichols, Russell, J., "Advances in the Emabond" Induction Welding Process for High-Performance Assembly of Demanding Thermoplastics", Assembly Technology Expo, 10 pages, September (2003)

11. Stokes, V., "Experiments on the Induction Welding of Thermoplastics", ANTEC/SPE Proceedings, Vol. 1, pp. 1288-1301, (2001).

12. Lee, C. and Kagan, V., "Angular Variation of Vibration Weld Joint Strength: In Horizontal Plane and in Vertical Plane", SAE Technical Paper Series \# 2002-01-0709, 4 pages, Detroit, MI (2002).

13. Kagan, V, "Forward to Better Understanding of Optimized Performance of Welded Joints: Local Reinforcement and Memory Effects for Polyamides", SAE International - Society of Automotive
Engineers, Detroit, MI, "Automotive Plastics: Components, Processes, and Technology" SP1575, 14 pages (2001).

14. Lee, C. S., and Kagan, V. et al., "Optimization of Vibration Weld Joint Strength for Plastic Air Intake Manifold", SAE Technical Paper \# 980730, pp. 111115, Detroit (1998).

15. Fisher, K., "30 Years of Development of Plastic Intake Manifolds", Proceedings of $7^{\text {th }}$ International Plastic Manifold Forum, Bilingual Edition, German and English, 34 pages, Spitzingsee, Germany, September (2000).

16. Kagan, V. A. et al., Method and Articles for Evaluating Welding Joints, U.S. Patent \# 6,193,133 (2001).

17. Kagan, V. A. et. al., Frictionally Welded Thermoplastic Articles Having Improved Strength, U.S. Patent \# 6,447,866 (2002).

\section{CONTACTS}

Russell J. Nichols, Operations Manager, Ashland Specialty Chemical Company, 49 Walnut Street, Norwood, NJ 07648. Phone: (201) 767-7400 x2230. Fax: (201) 767-3608. E-mail: rnichols@ashland.com

Val A. Kagan, Technical Adviser, 122 Edgefield Drive, Morris Plains, NJ 07828-1234. Phone: (973) 267-8329. E-mail: kaganv@yahoo.com

\section{KEY WORDS}

Induction, electromagnetic, insert, nylon, polyamides, injection molding, fiber-glass, reinforcement, mechanical properties, strength, burst pressure, optimized, automotive, under-the-hood, load-bearing.

\section{DEFINITIONS, ACRONYMS, ABBREVIATIONS}

AIM: Air intake manifold.

ASTM: American Society of Testing and Materials

BK: carbon black (colored/pigmented)

DOE: design of experiments

GF: fiber-glass reinforcement

ISO: International Organization for Standardization

PA: polyamide (nylon)

PBT: polybutylene terephalate

PC: polycarbonate

PP: polypropylene

SAE: The Engineering Society for Advancing Mobility Land Sea Air and Space

Wt. - level of thermoplastic reinforcement (or filled) by weight in \% 